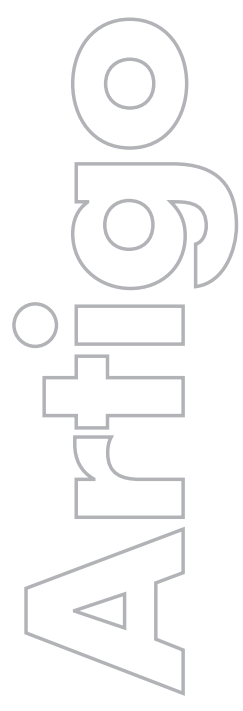

revista

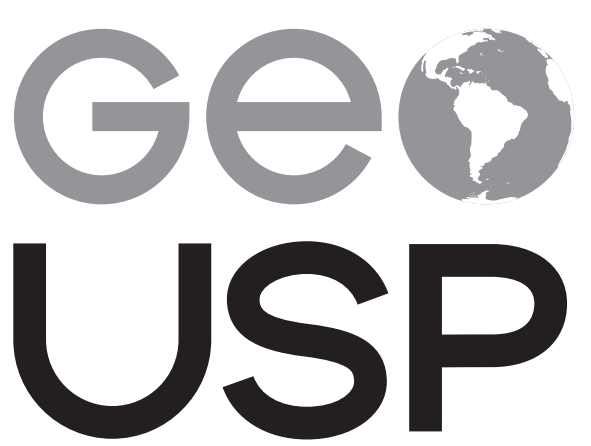

espaço e tempo

Volume $22 \cdot n^{\circ} 2(2018)$
Detecção de mudanças e modelagem preditiva do uso da terra e da cobertura vegetal do Pantanal de
Aquidauana-MS

Leandro Félix da Silva UFMS

Vitor Matheus Bacani UFMS

p. $437-456$

Como citar este artigo:

FÉLIX DA SILVA, L.; BACANI. V. M. Detecção de mudanças e modelagem preditiva do uso da terra e da cobertura vegetal do Pantanal de Aquidauana-MS. Geousp - Espaço e Tempo (Online), v. 22, n. 2, p. 437-456 mês. 2018. ISSN 2179-0892.

Disponível em: http://www.revistas.usp.br/geousp/article/ view/134659. doi: http://dx.doi.org/10.11606/issn.2179-0892. geousp.2018.134659.

\section{(c) (i) \$}

Este artigo está licenciado sob a Creative Commons Attribution 4.0 License. 


\title{
Deteç̧ão de mudanças e modelagem preditiva do uso da terra e da cobertura vegetal do Pantanal de Aquidauana-MS
}

\begin{abstract}
Resumo
Este estudo tem por objetivo analisar as mudanças ocorridas no uso da terra e na cobertura vegetal do Pantanal de Aquidauana, no Mato Grosso do Sul, entre os anos 1984, 1993, 2000 e 2015, e simular um cenário futuro para 2050. Os métodos utilizados para a simulação do cenário do ano 2050 foram baseados no processo analítico hierárquico (AHP) combinado com o modelo CA Markov (cadeias de Markov e autômatos celulares). $\bigcirc$ modelo elaborado para 2050 apresentou quatro classes: (1) vegetação nativa, (2) pastagem plantada, (3) solo exposto e (4) corpos d'água. A análise multitemporal a partir dos mapas de 1984, 1993, 2000 e 2015 e o modelo simulado para 2050 apontaram que haverá uma tendência de redução de áreas naturais, como vegetação natural e de corpos d'água, e o aumento das áreas relacionadas às ações antrópicas, como pastagem plantada e solo exposto.
\end{abstract}

Palavras-chave: Pantanal de Aquidauana. Tendência de mudanças espaciais. Processo analítico hierárquico (AHP). Cadeias de Markov-autômatos celulares.

\section{Changes detection and predictive modeling of land use and land cover in Aquidauana Pantanal Wetland-MS}

\begin{abstract}
This study aims to analyze changes in land use and land cover between 1984, 1993, 2000, 2015 and to simulate a future scenario for the year 2050. The methods used to simulate the future scenario for the year of 2050 were those based on the Hierarchical Analytical Process (AHP) combined with the CA Markov model (Markov Chain and Cellular Automata). The model elaborated for the year 2050 presented four classes that are: (1) Native Vegetation, (2) Planted Grassland, (3) Bare Soil and (4) Water bodies. The multitemporal analysis using the maps of 1984, 1993, 2000, 2015 and the model simulated for 2050 pointed out that over the analyzed years there will be a tendency to reduce natural areas such as natural vegetation and water bodies and the increase of related areas to anthropic actions such as planted pasture and bare soil.
\end{abstract}

Keywords: Pantanal of Aquidauana. Spatial trend of changes. Analystic hierarchy process (AHP). Markov Chains-cellular automata. 


\section{Introdução}

A maior parte da região pantaneira é constituída de propriedades particulares, caracterizada pela presença de extensas áreas de campos naturais, favorecendo a atividade pastoril, razão pela qual, a principal atividade econômica é a pecuária de corte conduzida de forma extensiva, cujo manejo tradicional, efetuado pelos pantaneiros acerca de mais de 200 anos (Santos et al., 2002). Considerando que a maior parte do Pantanal é formada por fazendas privadas (cerca de 95\%), qualquer plano de desenvolvimento/conservação sustentável da região deve levar em consideração o sistema de produção de gado de corte e a participação de seus proprietários (Santos et al., 2008).

Segundo Garcia (1981), a estruturação agrária da região é orientada por fenômenos ecológicos com características cíclicas variáveis, principalmente no que se refere aos aspectos hidrogeomorfológicos e climáticos que se refletem em inundações com diferentes intensidades têmporo-espaciais sobre a planície. Neste sentido, poderão observar-se remembramentos e desmembramentos dos estabelecimentos ajustados às condições produtivas locais e temporais da região. $\bigcirc$ tamanho "ideal" da empresa pecuária pantaneira poderá ser diferente do tamanho "ideal" da empresa pecuária de outras regiões do país, em função das características da região (topografia, fertilidade, clima etc.) e das condições de mercado (infraestrutura de comercialização, tipificação da produção etc.).

No Pantanal sul-mato-grossense e, desta forma, na área pantaneira do Município de Aquidauana, as inovações que romperam com a lógica de organização socioespacial do sistema na pecuária nos últimos 20 anos estão promovendo a transformação do espaço rural do Pantanal de Aquidauana para um novo ordenamento, mais diversificado e complexo, coerente com as tendências de superação da ordem produtivista, indo em direção ao paradigma pós-produtivista do século XXI (Araújo, 2011).

Ainda segundo a autora acima observam-se as tentativas para que a pecuária pantaneira do município fosse reestruturada sob a égide do paradigma da modernização agrícola vivida no Brasil a partir de 1970. As formas e conteúdo deste paradigma, que vem sendo incorporado até o momento atual na região, têm como objetivo intensificar a produção regional e aumentar a lucratividade dos criadores. Tem como meio, a substituição do pasto nativo por espécies exóticas; novas práticas de manejo do animal e das pastagens, como o melhoramento genético e a divisão do pasto em invernadas menores rotacionadas e a engorda por confinamento; a adesão de novas tecnologias e sistemas de gestão, como a articulação com os laboratórios e empresas agrícolas que trazem conteúdos de gestão e manutenção do sistema produtivo; além da presença de novos capitais. Tudo isso tornou a pecuária pantaneira mais capitalizada e com uma produção regional mais competitiva nos mercados nacional e internacional (Araújo, 2011).

$\bigcirc$ desenvolvimento de todos esses fenômenos também pode ser impresso na paisagem e estão ligados ao uso e cobertura da terra. $\bigcirc$ "uso da terra", entre as várias definições existentes, está geralmente associado às atividades conduzidas pelo homem na exploração dos recursos ambientais e relacionadas à função socioeconômica. A "cobertura da terra" é definida como o conjunto de elementos naturais além das construções artificiais que recobrem a superfície da terra (IBGE, 2013).

Os estudos sobre mudanças de uso e cobertura da terra inicialmente eram voltados apenas para a detecção de mudanças da paisagem e entendimento das forças dirigentes, e ao longo dos anos têm direcionado o foco da investigação para a modelagem de sistemas, para a previsão de mudanças e exploração de possíveis cenários futuros (Houet et al., 2010). 
O objetivo não é prever o futuro de forma determinística, mas sim representar as possibilidades de desenvolvimento sobre condições específicas que podem auxiliar na implementação de políticas e intervenções ambientais, na tomada de decisão e mitigação de potenciais consequências negativas das ações (Oliveira, 2012). Portanto, a projeção de paisagens futuras requer a consideração das tendências passadas, processos atuais de mudança do uso da terra e a incorporação de cenários plausíveis (Houet et al., 2010).

Segundo Paegelow e Camacho (2008), a simulação de um estado futuro de uma paisagem é possível por meio da aplicação de três modos de análise: cadeias de Markov (Usher, 1979; Acevedo; Urban; Ablan, 1995), avaliação multicriterial (Wu; Webster, 2000) e cadeias de Markov acopladas a um algoritmo de autômato celular.

Este estudo teve por objetivo simular um cenário futuro para o ano 2050, por meio da avaliação multicriterial (método AHP) e das técnicas de cadeias de Markov e autômatos celulares (CA Markov) para o Pantanal de Aquidauana, MS.

\section{Metodologia}

\section{Localização da área de estudo}

A área de estudo é o Pantanal de Aquidauana que tem aproximadamente 507.529,00 ha, localizado entre os paralelos $19^{\circ} 14^{\prime} 32^{\prime \prime} \mathrm{S}$ e $20^{\circ} 26^{\prime} 43^{\prime \prime} \mathrm{S}$ e os meridianos $55^{\circ} 06^{\prime} 42^{\prime \prime} \mathrm{W}$ e 56 04' 42" W. Situado no sudeste do Pantanal brasileiro, faz limite com o Pantanal da Nhecolândia ao norte, a serra de Maracajú, ao leste, os Pantanais do Aboral e do Miranda a oeste e ao sul encontra-se regiões de altitudes mais elevadas com cerrados e áreas de pastagens plantadas. Inserido dentro do Município de Aquidauana, no estado do Mato Grosso do Sul, conforme demonstra a Figura 1 .

\section{Figura 1 - Mapa de localização do Pantanal de Aquidauana, segundo a delimitação desenvolvida por Silva, J. et al. (1998)}
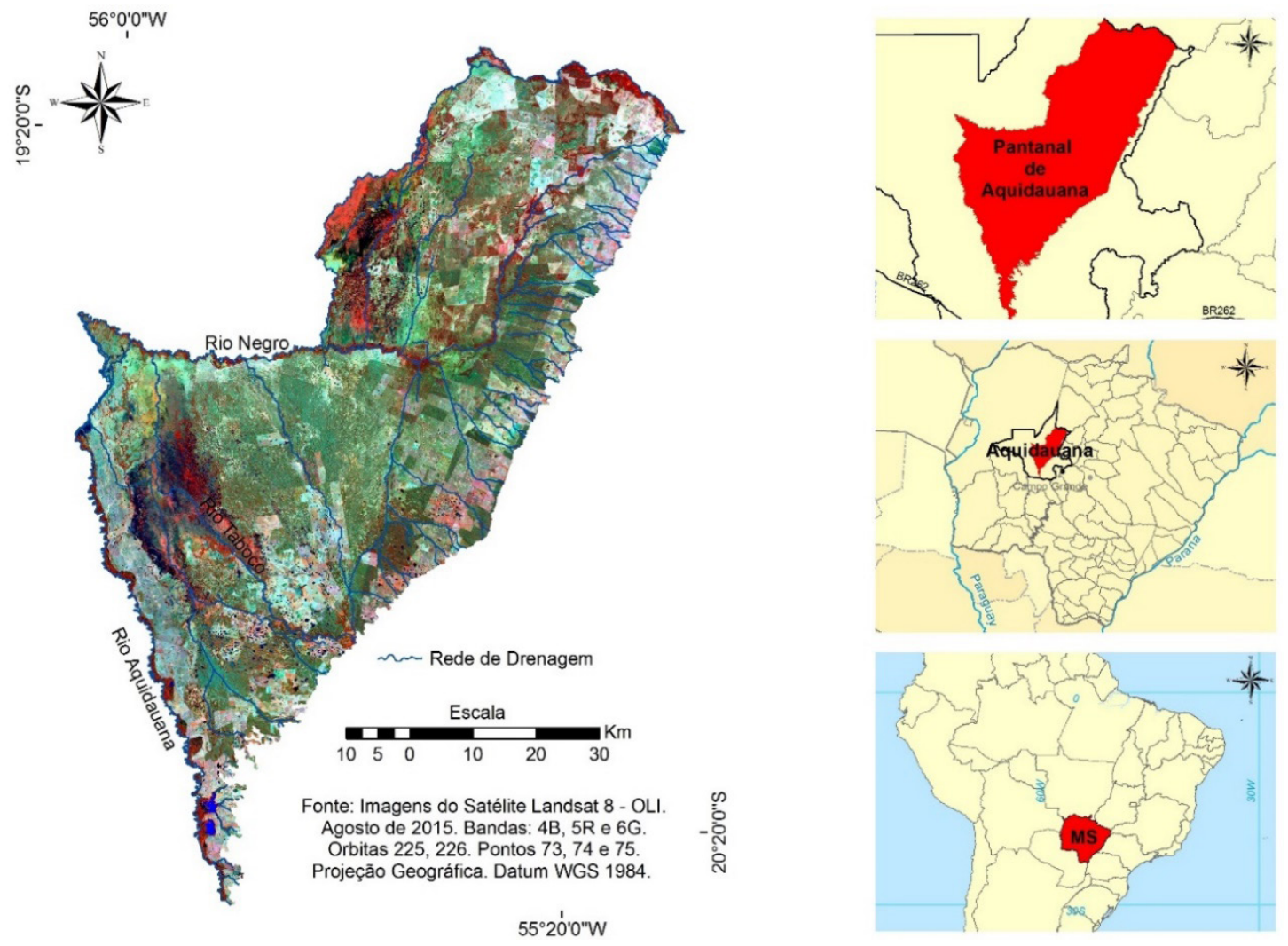
A cobertura vegetal do Pantanal de Aquidauana é formada por fisionomias específicas das regiões de savanas, do tipo florestada, arbórea, parque e gramíneo-lenhosa, com e sem florestas de galeria; áreas de formações pioneiras; áreas de tensões ecológicas e contatos florísticos de savana com formações pioneiras (ecótono) e as áreas de savana com floresta estacional semidecidual submontana (encrave); vegetação aluvial arbórea, arbustiva, herbácea ao longo dos flúvios (vegetação ciliar); áreas de influência antrópicas: vegetação secundária de savana e de pastagem plantada em região de savana e massas d’água segundo o projeto GeoMS (Silva, J. et al., 2011).

A principal atividade econômica na área de estudo é a pecuária extensiva. Entre as décadas de 1990 e 2000, a pecuária pantaneira de Aquidauana passou por profundas transformações, devido à incorporação de técnicas modernas no contexto de globalização e flexibilização produtiva adotada pela maioria dos produtores e suas propriedades, entre elas a criação de novas invernadas, novas formas de confinamento e principalmente substituição completa ou de $90 \%$ de áreas de pastagem nativa por pastagens exóticas introduzidas (Araújo, 2011), ocasionando uma rápida transformação nos modos de uso da terra e principalmente na paisagem da região.

\section{Procedimentos metodológicos}

Primeiramente optou-se pela utilização de imagens de sensores orbitais, produtos de sensoriamento remoto da família Landsat. Os produtos da família Landsat são dedicados exclusivamente à observação dos recursos naturais terrestres e por contemplar todo o recorte temporal estipulado para o estudo.

Foram utilizadas imagens dos anos 1984, 1993 e 2000 dos satélites Landsat 5, sensor TM (Thematic Mapper), órbitas ponto 225/74, 225/73 e 226/74, bandas 1, 2, 3, 4, 5, e 7 , todas do mês de agosto; imagens do satélite Landsat-8, sensor OLI (Operational Land Imager), órbitas ponto 225/74, 225/73 e 226/74, bandas 1, 2, 3, 4, 5, 6, 7 e 8, de 9 de agosto de 2015. A escolha pelo referido mês foi devido à disponibilidade de imagens para todos os anos mapeados livre de nuvens.

\section{Classificação de imagens}

O método de classificação utilizado para o mapeamento do uso da terra e da cobertura vegetal das imagens orbitais foi baseado nas técnicas de classificação orientada ao objeto OBIA (object-based image analysis) e pautou-se nas seguintes etapas: a) pré-processamento; b) segmentação; c) classificação e d) validação estatística do mapeamento.

As etapas (a) pré-processamento e (d) validação estatística foram processadas no software ENVI 5.1 (Exelis Visual Information Solutions, 2014) e as etapas (b) segmentação e (c) classificação dos alvos no software e Cognition 8.0 (Trimble Geospatial, [s.d.]).

\section{Pré-processamento}

A primeira etapa foi desenvolvida no software ENVI 5.1 (Exelis Visual Information Solutions, 2014), e se baseou na correção radiométrica das imagens de 1984, 1993, 2000 dos satélites Landsat 5/TM e a de 2015 do Landsat-8/OLI. Logo após todas as imagens terem 
sido corrigidas radiometricamente, foram submetidas ao processo de correção atmosférica por meio da ferramenta FLAASH Atmospheric Correction. Por último, as imagens corrigidas atmosfericamente passaram pelo processo de normalização, a partir da aplicação de uma função gaussiana, com a ferramenta Band Math.

\section{Segmentação}

A segmentação foi feita no software eCognition 8.0 (Trimble Geospatial, [s.d.]) e partiu da utilização da árvore de processo (process tree) no qual foram ajustados parâmetros de descrição como o algoritmo de segmentação a ser utilizado (multiresolution segmentation) para as quatro datas. Além do ajuste de elementos como escala, compacidade e forma.

\section{Classificação}

A classificação das imagens foi executada por meio do classificador Nearest Neighbor (vizinho mais próximo) disponível no software eCognition 8.0 (Trimble Geospatial, [s.d.]). Antes de executar a classificação, acrescentaram-se alguns parâmetros por meio da ferramenta de edição Edit Standard Nearest Neighbor Feature Space, tomados como critérios que ajudam a potencializar o classificador na separação e identificação dos objetos na imagem. Esses critérios foram o NDVI (normalized difference vegetation índex, ou índice de vegetação por diferença normalizada), o NDWI (normalized difference water índex, oi índice de água por diferença normalizada), médias de refletância das bandas (1, 2, 3, 4, 5 e 6) das imagens do satélite Landsat 5/TM e (1, 2, 3, 4, 5, 6 e 7) das imagens do satélite Landsat 8/OLI, geometria (área, índice de largura, largura e comprimento) e forma (assimetria, índice de borda, compacidade, índice de forma).

\section{Validação estatística}

A validação estatística da classificação foi calculada a partir da distribuição aleatória de pontos de controle para cada imagem (1984, 1993, 2000 e 2015). Foram distribuídos por volta de 800 pontos de verdade terrestre incluindo pontos obtidos a campo por meio de GPS (global positioning system) para cada imagem classificada pelo software ENVI 5.1 (Exelis Visual Information Solutions, 2014).

Utilizou-se como parâmetro estatístico a Matriz de Confusão (Congalton, 1991), a matriz de confusão fornece a base para descrever a precisão da classificação e caracterizar os erros, ajudando a refinar a classificação. De uma matriz de confusão podem ser derivadas várias medidas de precisão da classificação, sendo o Índice Kappa e a Acurácia Global algumas das mais conhecidas (Foody, 2002).

As medidas de precisão utilizadas para validar as quatro imagens classificadas foram o Índice Kappa (equação 1) que consiste em uma técnica multivariada discreta usada na avaliação da precisão temática e utiliza todos os elementos da matriz de confusão no seu cálculo (Figueiredo; Vieira, 2007). 


$$
\text { equação (1) } \hat{K}=\frac{N \sum_{i=1}^{n} x_{i i}-\sum_{i=1}^{n}\left(x_{i+} \cdot x_{+i}\right)}{N^{2}-\sum_{i=1}^{k}\left(x_{i+} \cdot x_{+i}\right)}
$$

Onde:

$\hat{K}$ : valor estimado Kappa;

$k$ : número de linhas;

$x_{i}$ : número de observações na linha $i$ e coluna $i$;

$\sum_{i=1}^{k} x_{i i}$ : soma dos elementos da matriz em sua diagonal principal;

$x_{i+}$ : soma total das observações para as linhas;

$x_{+i}$ : soma total das observações para as colunas;

$N$ : número de observações total.

E a acurácia global (equação 2), calculada a partir da divisão da soma da diagonal principal da matriz de erros xii, pelo número total de amostras coletadas $N$, ou seja:

$$
\text { equação (2) Acurácia } a_{\text {global }}=\left(\frac{\sum_{i=1}^{k} x_{i i}}{N}\right)
$$

E por último os valores obtidos do Índice Kappa e da acurácia global para cada imagem classificada, foram comparados aos limiares de qualidade de concordância estabelecidos por Landis e Koch (1977) no Quadro 1:

\section{Quadro 1 - Qualificação de acordo com o Índice Kappa}

\begin{tabular}{c|c}
\hline índice kappa & concordância \\
\hline 0,00 & péssima \\
\hline 0,01 a 0,20 & ruim \\
\hline 0,21 a 0,40 & razoável \\
\hline 0,41 a 0,60 & bom \\
\hline 0,61 a 0,80 & muito bom \\
\hline 0,81 a 1,00 & excelente \\
\hline \multicolumn{2}{|c}{ fonte: Landis e Koch (1977). }
\end{tabular}




\section{Modelagem preditiva de uso e cobertura da terra e da cobertura vegetal}

A simulação das mudanças no uso da terra e da cobertura vegetal e sua distribuição espacial para um cenário futuro de 2050 foi realizada em ambiente IDRISI Selva 17.0 (Eastman, 2011), utilizando como base o modelo CA Markov que integra as teorias das cadeias de Markov e autômatos celulares. $\bigcirc$ modelo CA Markov vem sendo amplamente usado para modelar e simular dimensões e tendências futuras nas mudanças no uso da terra e cobertura vegetal (Dalmas, 2013; Bacani et al., 2016). E seguiu as etapas abaixo (Figura 2).

\section{Figura 2 - Fluxograma das etapas percorridas para modelagem}

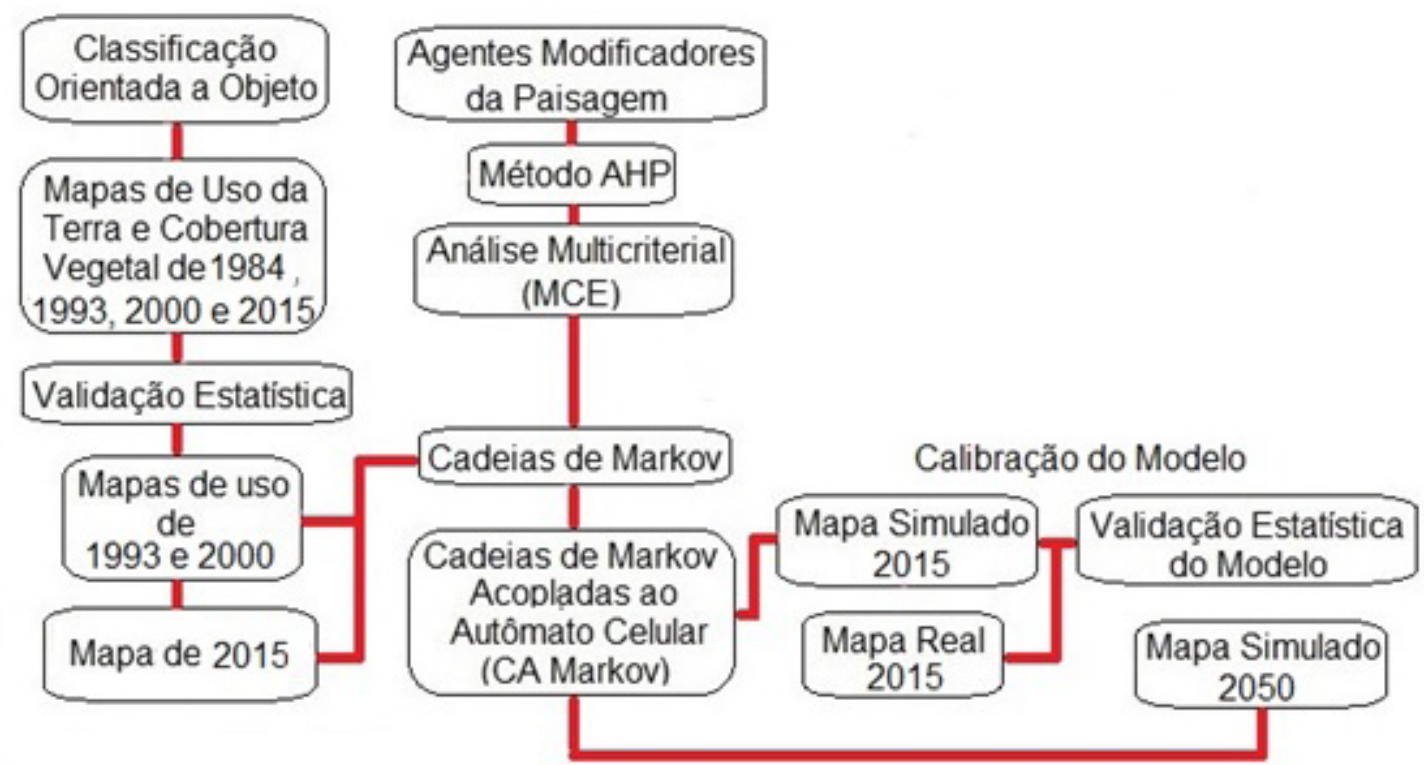

\section{Agentes modificadores}

Os agentes modificadores do uso da terra e da cobertura vegetal no Pantanal de Aquidauana utilizadas como variáveis explicativas são quatro: (1) áreas de transição de mudanças da vegetação nativa para pastagem plantada entre os anos 1993 e 2015, extraídas por meio da ferramenta LCM (land change modeler), acopladas ao software IDRISI Selva 17.0 (Eastman, 2011), (2) vias de acesso (estradas) vetorizadas em formato Shapefile (shp) a partir de imagens do satélite RapidEye e de imagens Google Earth, (3) limites das propriedades e (4) sedes das fazendas, todos adquiridos através de download no site do INCRA ([s.d.]).

Na sequência, para cada variável, foram criados mapas de distância por meio do algoritmo matemático que calcula a distância euclidiana, a partir das ferramentas Arc Toolbox - Spatial Analyst Tools - Distance - Euclidean Distace. Em seguida, as quatro variáveis foram todas classificadas por meio da lógica Fuzzy para determinar as áreas em que as influências foram maiores ou menores, a partir das seguintes ferramentas: Overlay - Fuzzy Membership, no software ArcGis 10.2 (ESRI, 2012). A Figura 3 demonstra os agentes modificadores já classificados pela lógica Fuzzy. 


\section{Figura 3 - Agentes modificadores classificados pela lógica Fuzzy}

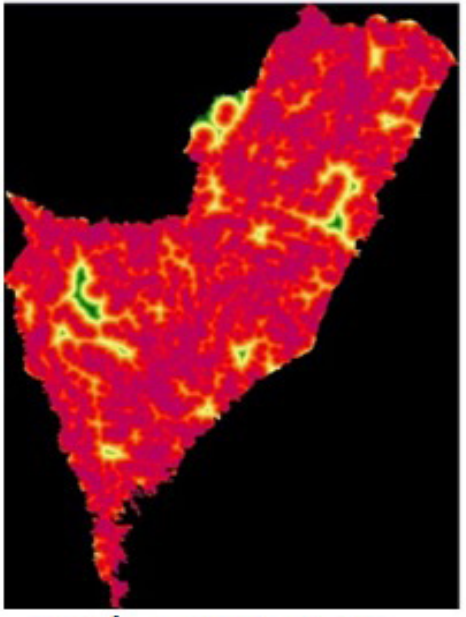

(1) Áreas de Transição

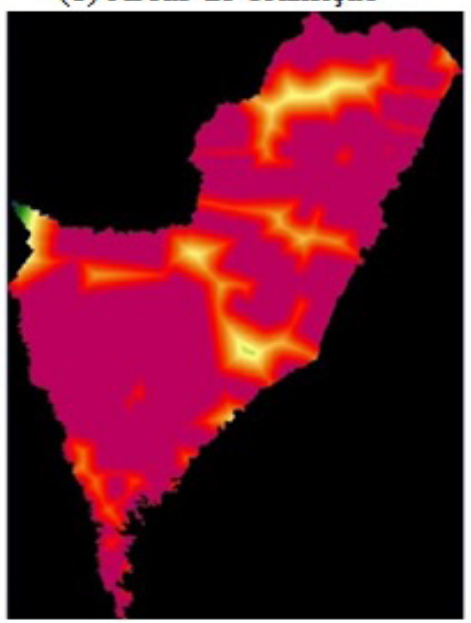

(3) Limites das Propriedades

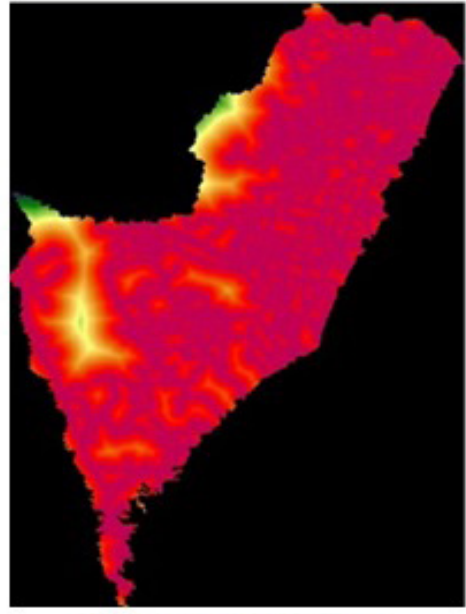

(2) Vias de Acesso

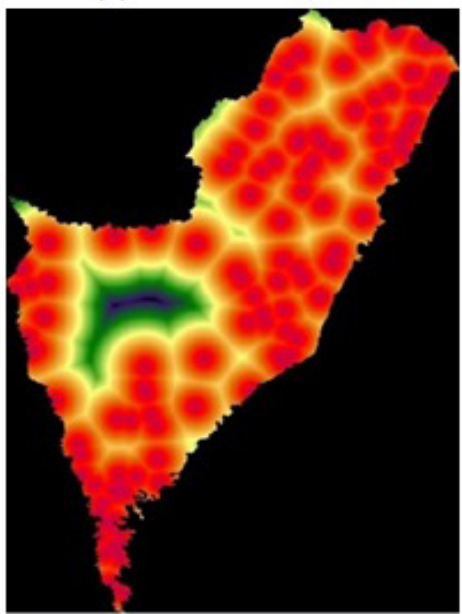

(4) Sede das Fazendas

fonte: Eastman (2011).

Os valores próximos de 0.00 representam as menores áreas de influência, enquanto mais próximos de 1.00 representam maiores áreas de influência na transformação.

\section{Método AHP e análise multicriterial}

As variáveis explicativas foram submetidas ao método AHP (analystic hierarchy process, ou processo analítico hierárquico) para a aplicação de valores de acordo com o nível que cada variável pode ter para influenciar as transformações do uso da terra e cobertura vegetal, por meio das seguintes ferramentas GIS Analysis - Decision Support - Weight. Em seguida foram aplicados valores da relação de importância que cada variável tem uma sobre a outra, esses valores variam em uma escala que vai de less important (menos importante) a more important (muito importante).

Os valores de importância são aplicados por meio de uma tabela que cruza os valores de cada variável (Figura 4) e como resultado apresenta uma combinação de valores hierarquicamente organizado que vai do mais importante ao menos importante dos fatores que podem influenciar as mudanças no uso da terra e cobertura vegetal. 
Figura 4 - Tabela com valores das variáveis explicativas no método AHP

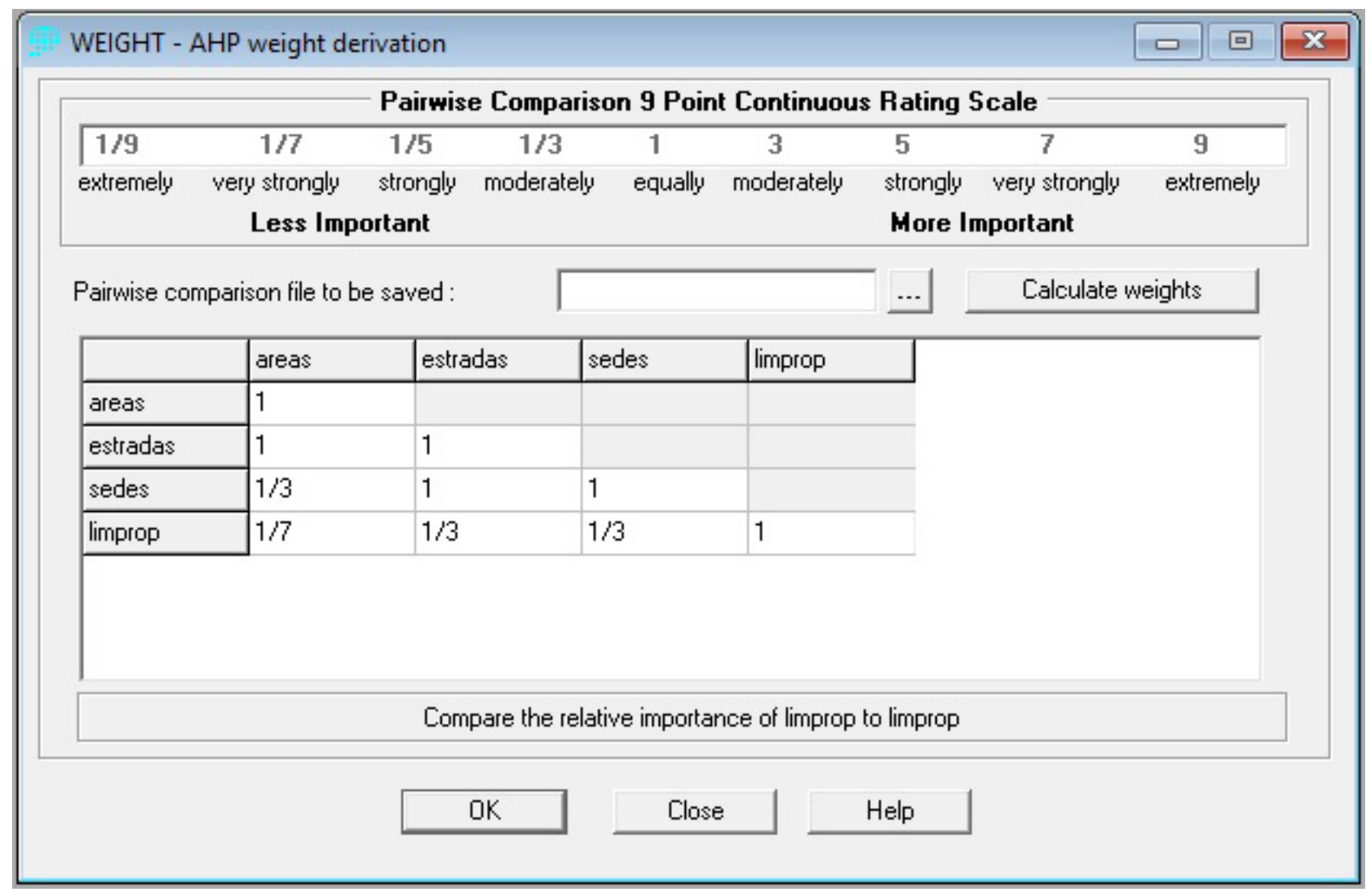

fonte: Eastman (2011).

Por fim, a tabela de resultado gerada pelo método AHP é submetida à análise multicriterial por meio das ferramentas GIS Analysis - Decision Support - MCE, no software IDRISI Selva 17.0 (Eastman, 2011), o que resultou em uma espacialização da combinação entre as variáveis e demonstrou as áreas de maiores influências que variam de 0 a 1 nas mudanças por meio de um mapa.

\section{Calibração do modelo}

A calibração do modelo partiu da comparação entre o mapa simulado para 2015 e o mapa real, utilizando os mapas dos anos 1993 e 2000 no módulo Markov, no qual também foi adicionando o mapa resultado da análise multicriterial (MCE). Em seguida os mapas de 1993 e 2000 foram inseridos no módulo CA_Markov gerando o mapa simulado para 2015.

Na sequência, o mapa simulado para 2015 foi submetido à avaliação estatística e comparado com o mapa real de 2015 por meio do Índice Kappa (Landis; Koch, 1977) e a Matriz de Confusão (Congalton, 1991) utilizando as ferramentas GIS Analysis - Decision support ERRMAT. E por último, o mapa simulado para 2015 foi submetido a mais uma validação, por meio do módulo Validate, por apresentar análises estatísticas mais completas de validação além do Kappa Standart (padrão), no qual foram utilizados também os valores do Kappa for location e Kappa for quantity, valores estes muito utilizados para validação de modelagem a partir de mapas de mudanças (Carvalho, 2015; Bacani et al., 2016). 


\section{Simulação do cenário para 2050}

A simulação do cenário futuro foi executada por meio das ferramentas Modeling - Environmental/SimulationModels - Markov, no qual foram inseridos os mapas de 1993 e 2015, o que gerou matrizes de transições para futuro referente as classes estabelecidas (1) vegetação nativa, (2) pastagem plantada, (3) solo exposto e (4) corpos d'água. Na sequência foi inserido o mapa resultado da análise multicriterial (MCE) no lugar da matriz de transição número 2 referente a pastagem plantada, que foi renumerado com o mesmo número (2) e reagrupado as outras matrizes de transição denominadas Raster Group.

Por último, por meio do CA_Markov foram inseridos o mapa de uso da terra e cobertura vegetal de 2015 como base, áreas de transição resultantes do Markov referentes aos anos 1993 e 2015 e as matrizes de transição também oriundas do Markov que foram reagrupadas (Raster Group). E foi aplicado o valor de 35 inteirações referente a 35 anos que serão projetados, no número de células autômatas, além de utilizar o filtro do autômato celular $5 \times 5$ Standart Contiguity Filter.

\section{Resultados e discussão}

\section{Uso da terra e cobertura vegetal: resultados dos parâmetros de segmentação e avaliação estatística do mapeamento}

A partir da técnica de classificação orientada a objeto (OBIA) que levou em consideração principalmente a segmentação como etapa fundamental na separação e identificação das classes, e que após vários testes de segmentação realizados obteve-se os valores de Escala, Compacidade e Forma dos objetos estão contidos no Quadro 2.

\section{Quadro 2 - Valores finais dos parâmetros obtidos na segmentação das imagens}

\begin{tabular}{cccc}
\hline ano & escala & compacidade & forma \\
\hline 1984 & 2 & 0,003 & 0,03 \\
1993 & 2 & 0,002 & 0,03 \\
2000 & 2 & 0.002 & 0,03 \\
2015 & 2 & 0,005 & 0,02 \\
\hline
\end{tabular}

Estes valores foram os que apresentaram melhores resultados de segmentação, conseguindo separar os alvos pré-definidos e posteriormente classificados, utilizando o classificador Nearest Neighbor como: vegetação nativa, pastagem plantada, solo exposto e corpos d'água.

O resultado da classificação foram quatro mapas temáticos de uso da terra e cobertura vegetal para o Pantanal de Aquidauana dos anos 1984, 1993, 2000 e 2015, todos qualificados como excelente, por meio dos pontos de controle aplicados na validação estatística utilizando o Índice de concordância Kappa e Acurácia Global. 
Os valores do desempenho do mapeamento estão no Quadro 3, segundo o estipulado por Landis e Koch (1977).

\section{Quadro 3 - Validação estatística pelo Índice Kappa e por acurácia global}

\begin{tabular}{ccccc}
\hline ano & índice kappa & qualidade & acurácia global & qualidade \\
\hline 1984 & 0,9277 & excelente & $93,5601 \%$ & excelente \\
1993 & 0,9141 & excelente & $92,3451 \%$ & excelente \\
2000 & 0,9290 & excelente & $93,6817 \%$ & excelente \\
2015 & 0,8711 & excelente & $93,6817 \%$ & excelente \\
\hline
\end{tabular}

A modelagem preditiva do uso da terra e cobertura vegetal do Pantanal de Aquidauana para 2050 manteve as quatro classes temáticas de uso da terra e cobertura vegetal já mapeadas anteriormente.

\section{Validação estatística do modelo}

A validação do modelo de uso da terra e cobertura vegetal para 2050 foi realizada por meio da comparação entre o mapa real de 2015 e o mapa simulado para o mesmo ano (2015) e avaliado pelo conjunto de parâmetros estatísticos Kappa, a partir da comparação integral pixel a pixel dos mapas real e simulado (Pontius; Millones, 2011).

Os valores obtidos do modelo simulado de 2015 avaliados pelo conjunto de parâmetros estatísticos Kappa (Pontius; Millones, 2011) disponíveis no módulo Validate do software IDRISI Selva 17.0 (Eastman, 20110 apresentaram valores acima de 0,80, classificado, de acordo com limiares de concordância estabelecidos por Landis e Koch (1977) como excelente, o que atesta o grau de confiabilidade do modelo. Os valores de validação do modelo segundo os parâmetros estatísticos Kappa e os limiares de concordância são apresentados no Quadro 4.

\section{Quadro 4 - Valores parâmetros estatísticos Kappa e limiar de concordância}

\begin{tabular}{ccc}
\hline parâmetro estatísticos kappa & valor & concordância \\
\hline kappa standart & 0,8269 & excelente \\
\hline kappa for location & 0,8688 & excelente \\
\hline kappa for no information & 0,8532 & excelente \\
\hline
\end{tabular}

A Figura 5 mostra a comparação entre os mapas real e simulado de uso da terra e cobertura vegetal, além das áreas similares e diferentes entre o mapa real de 2015 e o modelo. 
Figura 5 - Comparação entre os mapas de uso da terra e cobertura vegetal real de 2015 (real e simulado) e as diferenças entre ambos

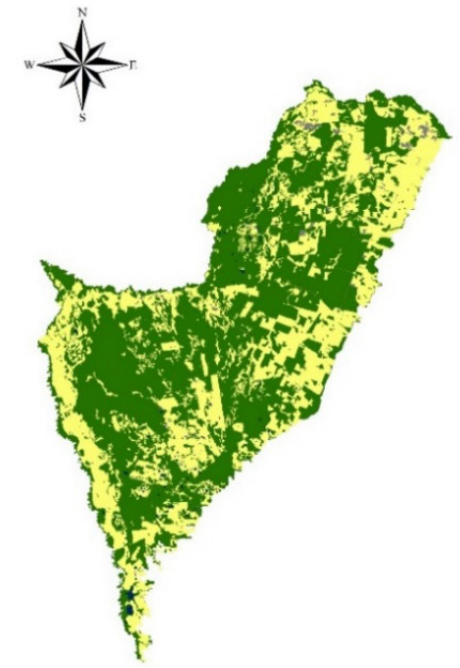

2015 Real

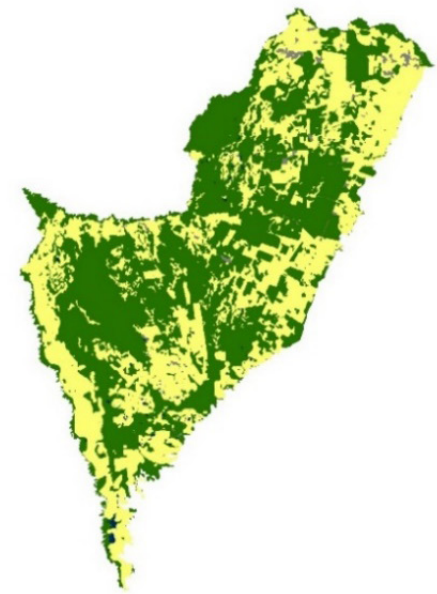

2015 Simulado

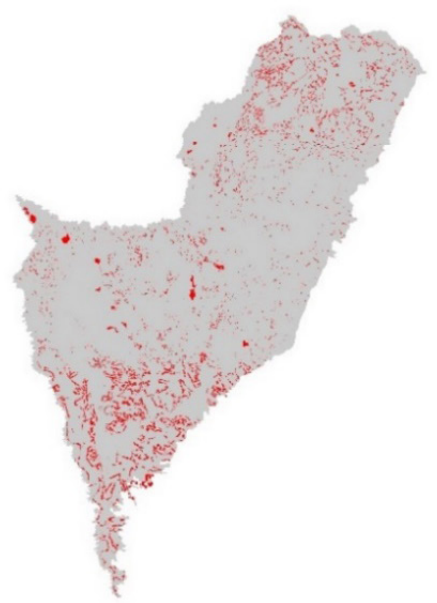

Diferença entre Real e Simulado

Vegetação Nativa

Pastagem Plantada Solo Exposto Corpos d'Água Áreas Similares entre Real e Simulado

\section{Simulação de mudanças futuras}

A partir dos mapas de uso da terra e cobertura vegetal entre os anos 1993 e 2015 utilizados por meio das cadeias de Markov para simular 2050, foi possível analisar os valores das mudanças das quatro classes de uso da terra e cobertura vegetal.

As cadeias de Markov geraram três informações sobre as classes de uso da terra e cobertura vegetal a serem simuladas: 1) Matriz de Probabilidade de Mudança, 2) Matriz de Área de Transição e 3) Imagens de Probabilidade de Mudança para cada classe de uso da terra e cobertura vegetal. Segundo Carvalho (2015), a escala utilizada para medir a probabilidade de mudança é entre valores de 0 (zero) a 1 (um), em que mais próxima de 0 seria a probabilidade nula de mudança e mais próxima de l, a maior.

Ao analisar a matriz de transição de probabilidade de mudanças, notou-se que há uma probabilidade maior de mudança nas classes pastagem plantada e vegetação nativa do que nas demais (Quadro 5).

Quadro 5 - Valores da matriz de probabilidade de mudança em cada classe temática de uso da terra e cobertura vegetal

\begin{tabular}{lllll}
\hline \multicolumn{5}{c}{ matriz de probabilidade de mudanças } \\
\hline classes & vegetação nativa & $\begin{array}{l}\text { pastagem plan- } \\
\text { tada }\end{array}$ & solo exposto & corpos d'água \\
\hline vegetação nativa & 0.5767 & 0.4454 & 0.0091 & 0.0035 \\
\hline pastagem plantada & 0.4107 & 0.6404 & 0.0104 & 0.0038 \\
\hline solo exposto & 0.3780 & 0.6050 & 0.0143 & 0.0027 \\
\hline corpos d'água & 0.0623 & 0.2726 & 0.0000 & 0.0559 \\
\hline
\end{tabular}


O resultado oriundo da matriz de probabilidade de mudanças indicou que a classe pastagem plantada e a vegetação nativa são as duas classes que tem a maior probabilidade de mudanças no futuro, baseado nas tendências de redução de uma classe, em relação ao aumento da outra que ocorrem ao longo dos anos registrados. Por meio dos mapas de um momento passado e de um momento presente, pôde-se apontar que estas classes são as que mais poderão sofrer mudanças no futuro analisado por meio das cadeias markovianas.

Os produtos resultantes do método AHP e da análise multicriterial (MCE), que foram utilizadas e adicionadas a matriz de probabilidade de mudanças oriundas das cadeias de Markov, permitiu por meio de uma forma ponderada e racionalizada adicionar elementos que contribuíram nas mudanças ocorridas no uso da terra e que estão relacionadas diretamente com o aumento da pastagem e do desmatamento.

Todas as variáveis explicativas utilizadas são produtos de ação antrópica ligadas principalmente com a atividade pecuarista que ao longo dos anos foi o principal agente nas transformações ocorridas no uso da terra e cobertura vegetal no Pantanal de Aquidauana.

No caso desta simulação do cenário futuro para o mapa de uso da terra e cobertura vegetal do Pantanal de Aquidauana é importante ressaltar que os mapas utilizados como base são do período seco, o que não se estende para um período de cheia uma vez que para uma região como o Pantanal de dinâmica hídrica extremamente complexa seria necessário para poder simular um período de cheia a utilização de outros elementos como modelos meteorológicos e hidrológicos.

\section{Modelo de uso da terra e da cobertura vegetal do Pantanal de Aquidaua- na para 2050}

A modelagem do uso da terra e da cobertura vegetal do Pantanal de Aquidauana para 2050 (Figura 6), por meio das cadeias de Markov acopladas a autômatos celulares (CA Markov), permitiu a reprodução de quatro classes temáticas: (1) vegetação nativa, (2) pastagem plantada, (3) solo exposto e (4) corpos d'água.

\section{Figura 6 - Modelo de uso da terra e cobertura vegetal para 2050}
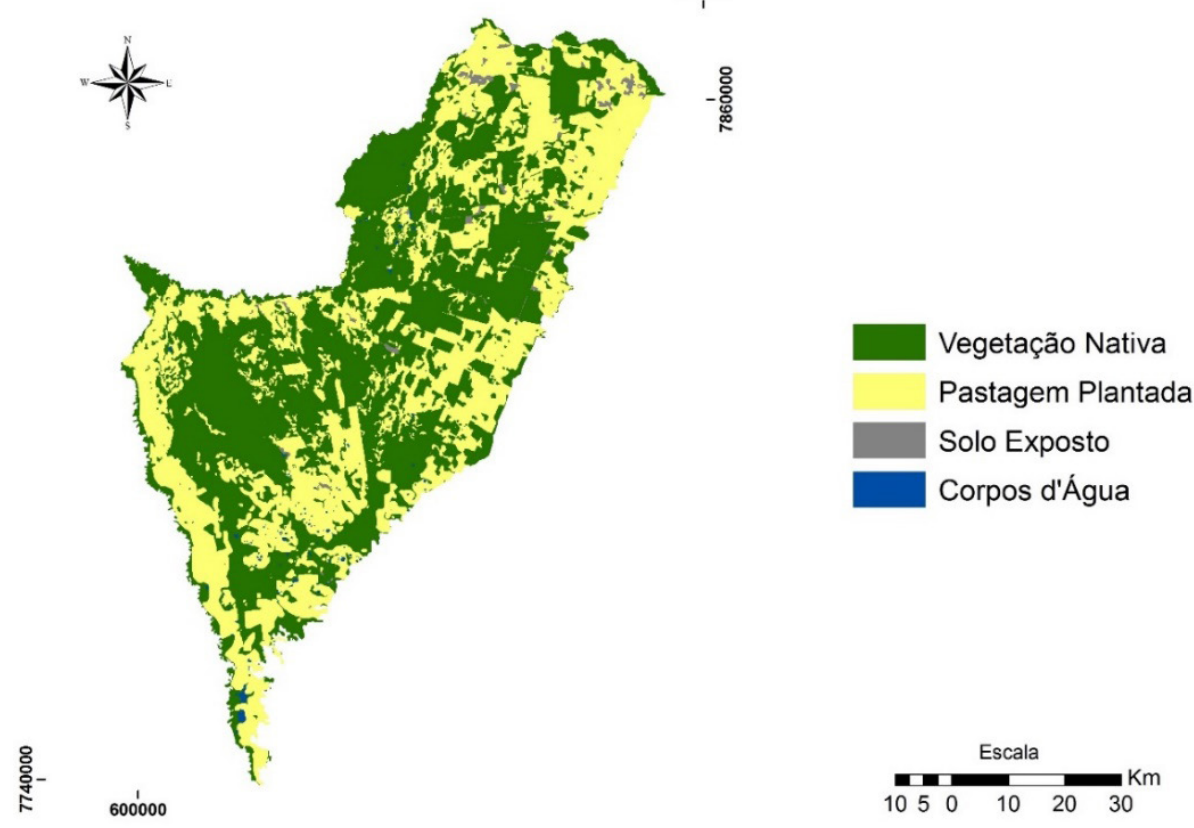
Em seguida, para o modelo de uso da terra e cobertura vegetal no ano 2050, foram quantificados os valores de cada classe temática em hectares (ha) e porcentagem (\%) (Quadro 6).

\section{Quadro 6 - Valores quantificados das classes de uso terra e cobertura ve- getal em 2050}

\begin{tabular}{ccc}
\hline classe & hectares (ha) & porcentagem (\%) \\
\hline vegetação nativa & $276.230,8000$ & $54,43 \%$ \\
\hline pastagem plantada & $224.247,8700$ & $44,18 \%$ \\
\hline solo exposto & $4.735,8900$ & $0,93 \%$ \\
\hline corpos d'água & $2.314,4400$ & $0,46 \%$ \\
\hline total & $507.529,0000$ & $100 \%$ \\
\hline
\end{tabular}

Para 2050, a vegetação nativa ocupará cerca de 54,43\% do Pantanal de Aquidauana, uma área de aproximadamente 276.230,8000 ha, enquanto as áreas ocupadas por pastagem plantada ocuparão cerca de 44,18\%, o equivalente a $224.247,8700$ ha da região.

A Figura 7 demonstra os valores em porcentagem de ocupação de cada classe de uso da terra e cobertura vegetal para 2050.

Figura 7 - Gráfico com as quatro classes temáticas mapeadas de uso da terra e cobertura vegetal para 2050

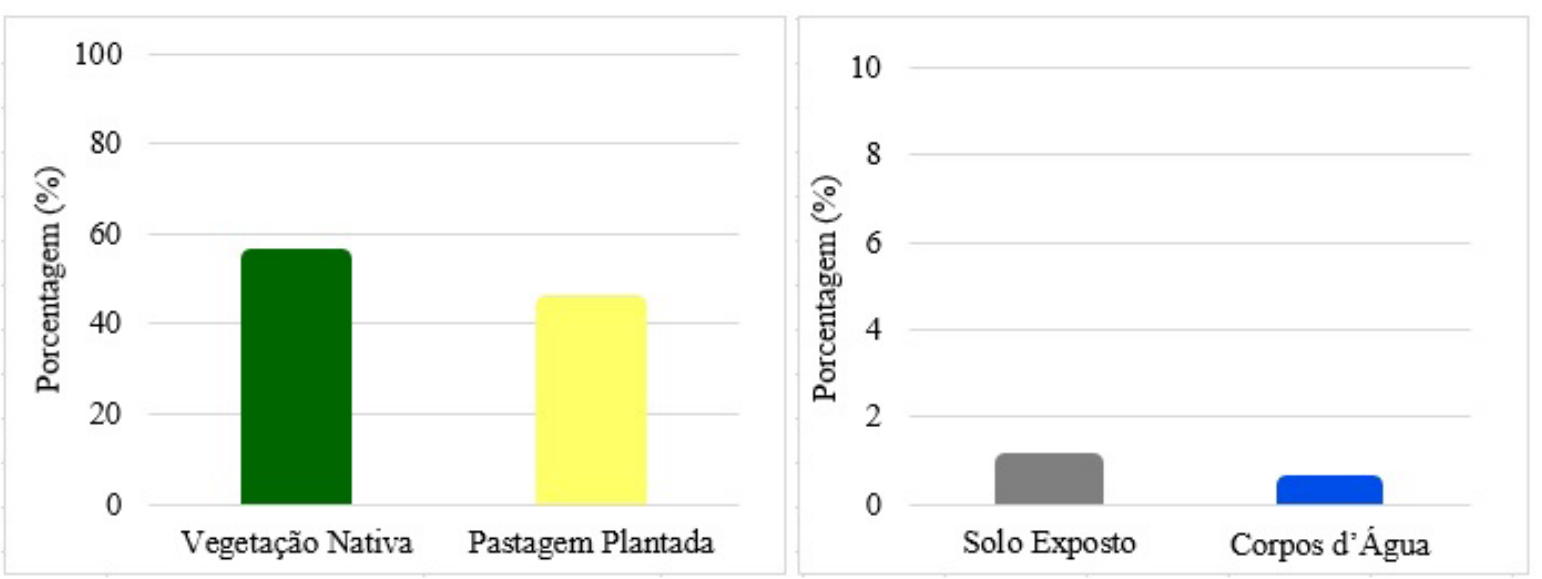

As áreas de solo exposto representarão cerca de 4.735,8900 ha, o mesmo que 0,93\% da região do Pantanal de Aquidauana, assim como as áreas de corpos d'água será de 2.314,4400 ha ocupando apenas $0,46 \%$ da região.

modelo de uso da terra e cobertura vegetal projetou que em um período de 35 anos as áreas de pastagem plantada ocuparão quase que metade da região do Pantanal de Aquidauana para 2050, podendo chegar muito próximo dos valores de ocupação das áreas de vegetação nativa, uma vez que na atualidade as áreas de vegetação nativa ainda são maiores e tem predomínio da cobertura vegetal na região do Pantanal de Aquidauana. 


\section{Análise multitemporal preditiva do uso da terra e cobertura vegetal}

O mapeamento de uso da terra e cobertura vegetal elaborado entre os anos 1984, 1993, 2000 e 2015 permitiu observar o comportamento das quatro classes mapeadas e sua evolução ao longo de 31 anos, logo para efeito de análise multitemporal mais ampliada também foi adicionado o modelo projetado para 2050. A Figura 8 demonstra a evolução espacializada por meio dos mapas de uso da terra e da cobertura vegetal de 1984 a 2050.

Figura 8 - Evolução do uso da terra e da cobertura vegetal de 1984 a 2050
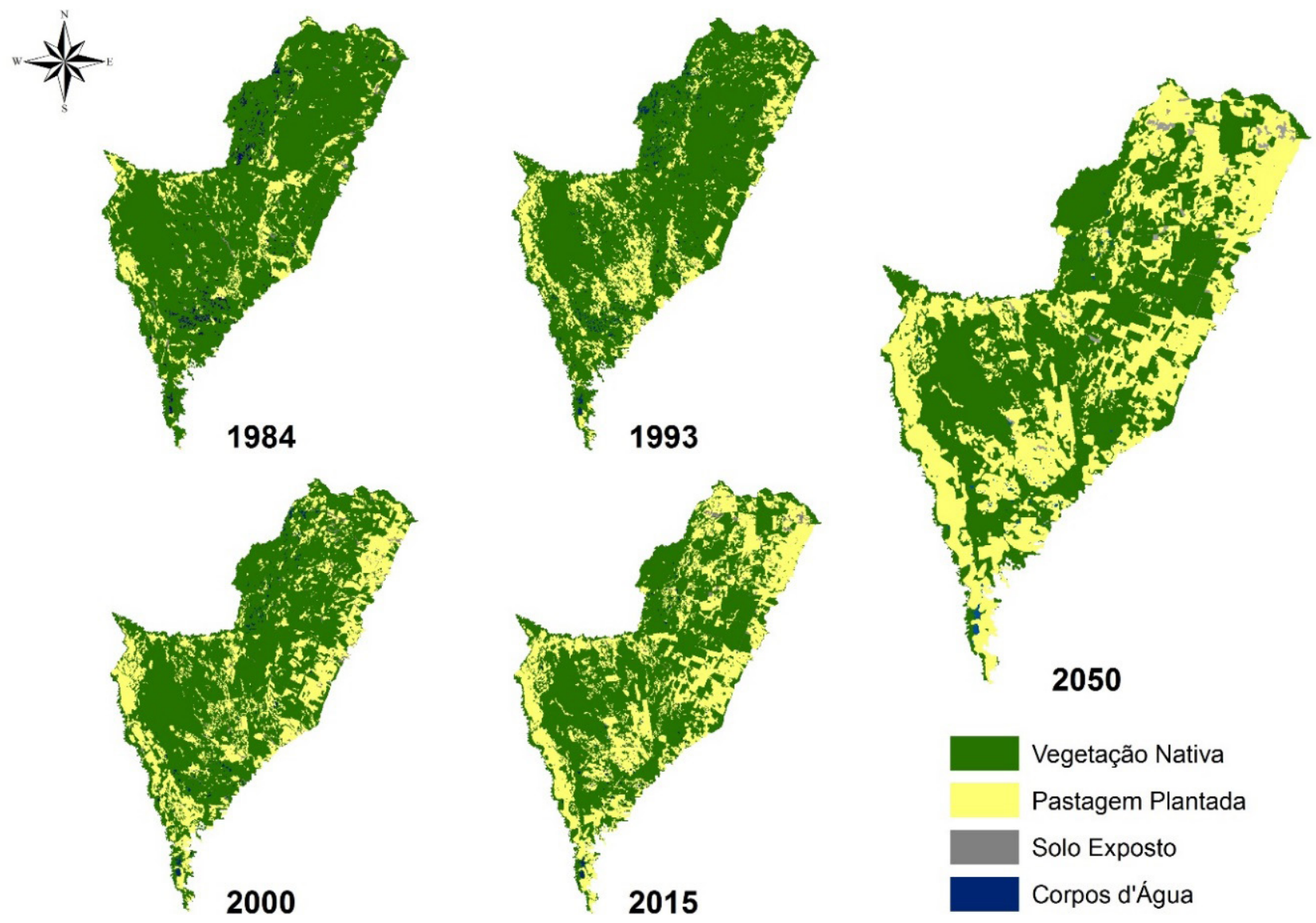

2050

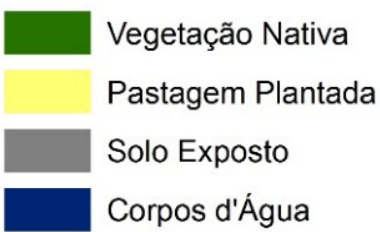

Em seguida, as classes de uso da terra e cobertura vegetal foram quantificadas em porcentagem (Quadro 7), mostrando o valor de cada classe no Pantanal de Aquidauana.

Quadro 7 - Valores quantificados das classes de uso terra e cobertura vegetal nos anos 1984, 1993, 2000, 2015 e 2050

\begin{tabular}{cccccc}
\hline classe/ano & 1984 & 1993 & 2000 & 2015 & 2050 \\
\hline vegetação nativa & $84,86 \%$ & $77,46 \%$ & $70,12 \%$ & $60,00 \%$ & $54,43 \%$ \\
\hline pastagem plantada & $12,89 \%$ & $20,17 \%$ & $28,49 \%$ & $38,74 \%$ & $44,18 \%$ \\
\hline solo exposto & $0,88 \%$ & $0,87 \%$ & $0,56 \%$ & $0,68 \%$ & $0,93 \%$ \\
\hline corpos d'água & $1,37 \%$ & $1,50 \%$ & $0,83 \%$ & $0,58 \%$ & $0,46 \%$ \\
\hline total & $100 \%$ & $100 \%$ & $100 \%$ & $100 \%$ & $100 \%$ \\
\hline
\end{tabular}


Ao analisar a evolução do uso da terra e da cobertura vegetal do Pantanal de Aquidauana levando em consideração o passado, o presente e projetando o futuro, ao todo totalizando um período de 66 anos, observou-se que a vegetação nativa entre o passado e o presente sofreu uma drástica redução de suas áreas de ocupação e que para o futuro projetado ela demonstra que continuará tendo tendências à redução.

Em 1984 as áreas de vegetação nativa eram de 84,86\%, em 1993 passaram a ser de 77,46\%, 2000 elas ocupavam 70,12\% e atualmente em 2015 a vegetação nativa recobre 60\% da região. Segundo o modelo projetado para 2050 ela ocupará uma área de cerca de 54,43\% do Pantanal de Aquidauana.

A Figura 9 demonstra o gráfico com classes de uso da terra e cobertura vegetal pareadas entre 1984 e 2050.

\section{Figura 9 - Gráfico com as quatro classes temáticas mapeadas de uso da terra e cobertura vegetal de 1984 a 2050}

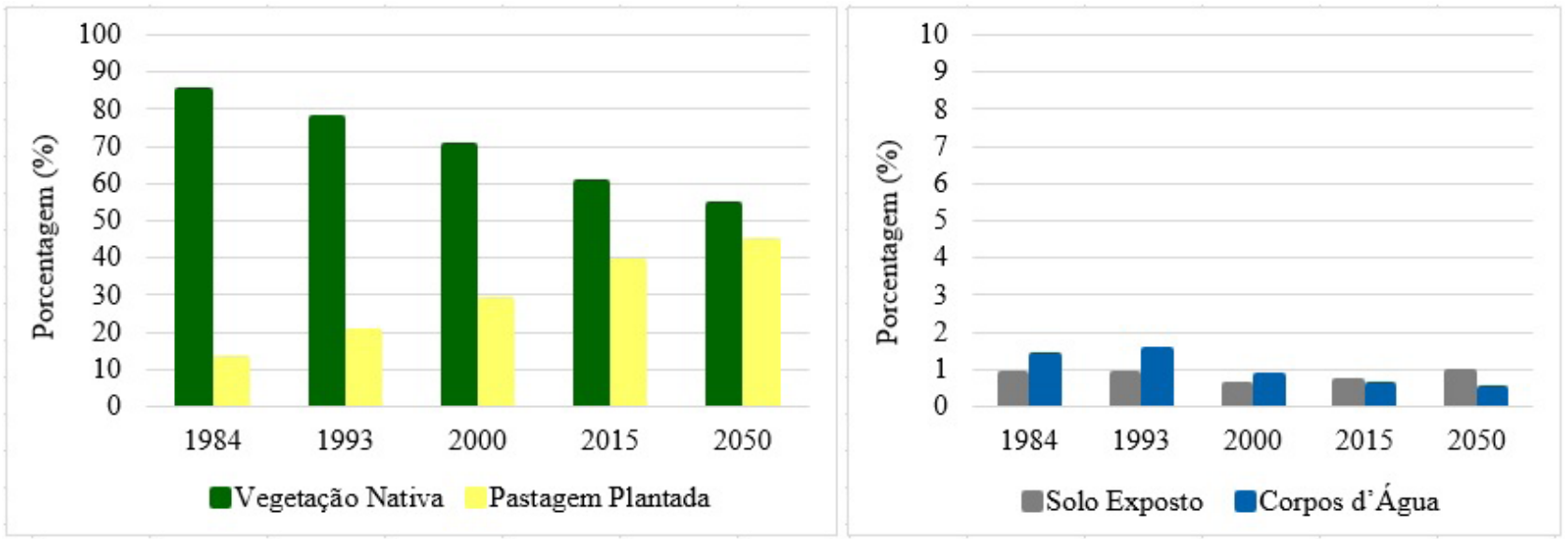

Já a evolução das áreas de pastagem plantada demonstra o comportamento inverso das áreas de vegetação nativa, a pastagem plantada ao longo dos anos aumentou em grandes proporções principalmente a partir da década de 2000 com as novas abordagens e técnicas de manejo na atividade de pecuarista conforme o descrito por Araújo (2011).

Para 1984, as áreas de pastagens plantadas representavam 12,89\% de área ocupada, já em 1993 ela aumenta e passa para 20,17\%. Em 2000, as áreas de pastagem plantada ocupavam 28,49\% e em 2015 é predominante em 38,74\% do Pantanal de Aquidauana. A projeção para 2050 aponta que 44,18\% da região será de pastagem plantada, o que confirma a tendência histórica de aumento da classe com passar dos anos.

Essa substituição da vegetação nativa por áreas de pastagem plantada no Pantanal de Aquidauana ocorre principalmente por desmatamento, prática já registrada em outros trabalhos, desenvolvidos por Silva, J. et al. (1998), Mourão et al. (2000), Araújo (2011), Silva e Bacani (2015) e Bacani et al. (2016), evidenciando a tendência ao aumento da classe pastagem plantada na região com o passar dos anos. 
As áreas de solo exposto entre os anos 1984 (0,88\%) e 1993 (0,87\%) não apresentaram alterações significativas. Em 2000, sua área é menor que a dos anos anteriores, representando cerca de 0,56\%. Em 2015, as áreas de solo exposto são de 0,68\%, maiores que o ano 2000, e, na simulação de 2050, representaram 0,93\% da região do Pantanal de Aquidauana. $\bigcirc$ aumento estará ligado principalmente a áreas desmatadas e à criação de novas vias de acesso (estradas).

Os corpos d'água é outra classe que também apresentou ao longo dos anos analisados grandes reduções de suas áreas 1984 (1,37\%), 2000 (0,83\%) e 2015 (0,58\%) apenas em 1993 $(1,50 \%)$ apresenta-se um aumento por se tratar de um ano mais úmido. Para 2050, áreas de corpos d'água tendem a redução e representará 0,46\% região do Pantanal de Aquidauana.

Ao analisar a partir de uma série histórica de mapas o comportamento do uso da terra e da cobertura vegetal para o Pantanal de Aquidauana que leva em consideração passado, presente e o futuro extraiu-se informações sobre as mudanças ocorridas e tendências de transformações futuras, o que permite, criar alternativas que busquem reduzir os impactos atuais, no intuito de poder minimizá-los ou saná-los no futuro, uma vez que as atividades econômicas exercidas nos modos de uso da terra devem respeitar os limites naturais do ambiente, para que se possa utilizar os recursos da maneira mais sustentável possível.

resultado apresentado pela modelagem para o futuro, quando comparado com presente e passado das classes analisadas demonstram uma coerência nos resultados projetados, alertando principalmente para as classes que sofrerão reduções como a vegetação nativa importante forma de cobertura vegetal e dos corpos d'água que compõe a rede hídrica, dois elementos de suma importância para manutenção equilibrio das planícies alagáveis do Pantanal de Aquidauana.

E o segundo resultado importante projetado foi o possível aumento das áreas de solo exposto e de pastagem plantada no futuro que ocupariam quase que a metade de toda área do Pantanal de Aquidauana. Tal aumento pode influenciar principalmente o aumento da temperatura ambiente e com a falta da cobertura vegetal nativa pode trazer alterações no ciclo hidrológico, uma vez que a região é regida obrigatoriamente pelo ciclo das águas, que podem desencadear um sério desequilibrio ecológico posteriormente econômico para atividades desenvolvidas na região.

\section{Conclusões}

O desenvolvimento do modelo preditivo de uso da terra e da cobertura vegetal para 2050 a partir do método AHP, da análise multicriterial (MCE) e dos autômatos celulares acoplados às cadeias de Markov apresentou resultados muito satisfatórios, os quais foram anexados aos mapas reais do passado e do presente utilizados na análise multitemporal, o que permitiu discutir as transformações ocorridas ao longo dos anos e projetar possíveis transformações no futuro relacionadas ao desmatamento e à atividade pecuarista.

A simulação do cenário futuro para 2050 indicou que, caso mantido o ritmo de mudança na paisagem do Pantanal de Aquidauana, conforme ocorrido nos últimos 30 anos, há tendência contínua de redução da vegetação natural em função da expansão das áreas de pastagem destinadas à pecuária de corte. Quando tomamos como referência o ano de partida do mapeamento (1984), outra possível mudança futura registrada foi o aumento das áreas de solo exposto e a redução da área superficial ocupada por corpos hídricos. 
O resultado da simulação futura desenvolvida não prevê de forma determinística e obrigatória que o futuro de cada classe será exatamente como projetado no modelo, mas apresenta projeções de possíveis situações que permitam ao planejamento socioambiental refletir sobre ações mitigadoras pensando no futuro, baseando-se nos registros das atividades desenvolvidas no presente e no passado.

Espera-se que os resultados obtidos com o uso das técnicas desenvolvidas e aplicadas nesta pesquisa possam auxiliar na tomada de decisão pelo poder privado, em parceria com o poder público, quanto ao desenvolvimento de gestão nos modos de uso da terra e da manutenção da cobertura vegetal, de maneira que se priorize a sustentabilidade e se pense na preservação e no futuro dos recursos naturais disponíveis no Pantanal de Aquidauana.

\section{Referências}

ACEVEDO, M. F; URBAN, D. L.; ABLAN, M. Transition and Gap Models of Forest Dynamics. Ecological Applications, Washington, v. 5, n. 4, p. 1040-1055, 1995.

ARAÚJO, A. G. J. A pecuária no Pantanal: novas tendências no processo de produção de Aquidauana, Mato Grosso do Sul. Dissertação (Mestrado em Geografia) -Universidade Federal do Rio de Janeiro, Rio de Janeiro, 2011.

BACANI, V. M.; SAKAMOTO, A.Y.; QUENÉOL, H.; VANNIER, C.; CORGNE, S. Markov chains-cellular automata modeling and multicriteria analysis of land cover change in the Lower Nhecolândia subregion of the Brazilian Pantanal wetland. Journal Applied Remote Sensing, v. 10, n. 1, p. 1-21, 2016.

CARVALHO, G. A. Contribuições metodológicas ao planejamento urbano: comparação de métodos de análise multivariada e modelo de simulação da paisagem urbana - aplicações na Regional Pampulha - Belo Horizonte, Minas Gerais - Brasil. Tese (Doutorado em Geografia) - Universidade Federal de Minas Gerais, Belo Horizonte, 2015.

CONGALTON, R. G. A review of assessing the accuracy of classifications of remotely sensed data. Remote Sensing of Environment, v. 49 n. 12, p. 1671-1678, 1991.

DALMÁS, F. B. Análise da evolução do uso e ocupação do solo na UGRHT - 11 e avaliação de cenários futuros em função de processos erosivos e de movimentos de massa utilizando técnicas de geoprocessamento. Tese (Doutorado em Recursos Minerais e Hidrogeologia) - Instituto de Geociências, Universidade de São Paulo, São Paulo, 2013.

EASTMAN, J. R. Guide to GIS and Imaging Processing. IDRISI Selva Manual: Version 17.0. Workcerster, MA: Clarks Labs of Clark University, 2011.

ESRI. ENVIRONMENTAL SYSTEMS RESEARCH INSTITUTE. ArcGIS for Desktop: Version 10.1. Redlands: ESRI, 2012.

EXELIS VISUAL INFORMATION SOLUTIONS. ENVI/software ENVI 5.1. Boulder, CO, 2014. 1 CD-Rom. 
FIGUEIREDO, G. C.; VIEIRA, C. A. O. Estudo do comportamento dos índices de exatidão Global, Kappa e Tau, comumente usados para avaliar a classificação de imagens do sensoriamento remoto. In: SIMPÓSIO BRASILEIRO DE SENSORIAMENTO REMOTO, 13., 2007, Florianópolis. Anais... Florianópolis, 2007. p. 5755-5762.

FOODY, G. M. Status of land cover classification accuracy assessment. Remote Sensing of Environment, v. 80, p. 185-201, 2002.

GARCIA, E. A. C. Estrutura fundiária no município de Corumbá, MS. Documentos Embrapa Pantanal - Circular Técnica, Corumbá, v. 6, p. 1- 31, 1981.

HOUET, T.; LOVELAND, T. R.; LAURENCE, H.; GAUCHEREL, C.; NAPTON, D.; SAYLER, K. Exploring subtle land use and land cover changes: a framework for future landscape studies. Landscape Ecology, v. 25, p. 249-266, 2010.

IBGE. INSTITUTO BRASILEIRO DE GEOGRAFIA E ESTATÍSTICA. Manual técnico de uso da terra. Manuais Técnicos em Geociências. 3a. ed. Rio de Janeiro: IBGE, 2013. v. 7

INCRA. INSTITUTO NACIONAL DE COLONIZAÇÃO E REFORMA AGRÁRIA. Disponível em: http://www.incra.gov.br/index.php/noticias-sala-de-imprensa/ noticias/9946-incra-lanca-complexo-de-assentamentos-em-aquidauana. Acesso em: 19 out. 2015.

Acervo fundiário. I3 Geolncra. Disponível em: http://acervofundiario.incra.gov.br/ acervo/acv.php. Acesso em: 3 ago. 2018.

LANDIS, J. R.; $\mathrm{KOCH}, \mathrm{G}$. G. The measurement of observer agreement for categorical data. Biometrics, v. 33, n. 1, p. 159-174, 1977.

LANDSAT OLI 8: imagem de satélite. Virginia: USGS, 2015. 1 fotografia área. Escala 1:100.000. Bandas 1, 2, 3, 4, 5, 6, 7 e 8.

LANDSAT TM 5: imagem de satélite. Virginia: USGS, 2000. 1 fotografia área. Escala 1:100.000. Bandas 1, 2, 3, 4, 5, e 7.

Virginia: USGS, 1993. 1 fotografia área. Escala 1:100.000. Bandas 1, 2, 3, 4, 5, e 7.

Virginia: USGS, 1984. 1 fotografia área. Escala 1:100.000. Bandas 1, 2, 3, 4, 5, e 7.

MOURÃO, G.; COUTINHO M.; MAURO, R.; CAMPOS, Z.; TOMÁS W.; MAGNUSSON, W. Aerial surveys of caiman, marsh deer and pampas deer in the Pantanal wetland of Brazil, Biological Conservation, v. 92, n. 2, p. 175-183, 2000.

OLIVEIRA, M. S. Deteç̧ão de mudanças de uso e cobertura da terra no Sinclinal Moeda (MG) no período de 1991 a 2011 e previsões de mudanças futuras através de modelo espacial de simulação. Dissertação (Mestrado em Análise e Modelagem de Sistemas Ambientais) - Universidade Federal de Minas Gerais, Belo Horizonte, 2012.

PAEGELOW, M.; CAMACHO, M. T. O. Modelling Environmental Dynamics: advances in geomatic solutions: Berlin: Springer Science E Business Media, 2008. 
PONTIUS, R. G.; MILLONES, M. Death to Kappa: birth of quantity disagreement and allocation disagreement for accuracy assessment. International Journal of Remote Sensing, v. 32, p. 4407-4429, 2011.

SANTOS, S. A.; CARDOSO, E. L.; SANTOS SILVA, R. A.; M. PELLEGRIN, A. O. Princípios básicos para a produção sustentável de bovinos de corte no Pantanal. Documentos Embrapa Pantanal, Corumbá, v. 37, p. 1-28, 2002.

SANTOS, S. A.; DESBIEZ, A. L. J.; BUAINAIN, M. U.; ABREU, U. G. P.; SANTOS, D.; SILVA, R. A. M. S.; SANTOS, R. C. R. Competitividade, sustentabilidade e cadeia produtiva bovina no Pantanal. Corumbá, MS: Embrapa Pantanal, 2008.

SILVA, J. S. V.; ABDON, M. M.; SILVA, M. P.; ROMERO, H. R. Levantamento do desmatamento do Pantanal brasileiro até 1990/91. Pesquisa Agropecuária Brasileira, v. 33, p. 1739-1745, 1998.

SILVA, J. S. V.; POTT, A.; ABDON, M. M.; POTT, V. J.; SANTOS, K. R. Projeto GeoMS: cobertura vegetal e uso da terra do estado do Mato Grosso do Sul. Campinas, SP: Embrapa Informática Agropecuária, 2011.

SILVA, L. F; BACANI, V. M. Análise multitemporal do uso da terra e cobertura vegetal no pantanal de Aquidauana com o uso de geotecnologias. REDE - Revista Eletrônica PRODEMA, Fortaleza, v. 9, n. 2, p. 27-40; 2015.

TRIMBLE GEOSPATIAL. Software e Cognition Developer 8.0. Disponível em: http:// www.ecognition.com/suite/ecognition-developer. Acesso em: 16 abr. 2015.

USHER, M. B. Markovian Approaches to Ecological Sucession. Journal of Animal Ecology, London, v. 48, n. 2, p. 413-426, 1979.

WU, F; WEBSTER, C. J. Simulating artificial cities in a GIS environment: urban growth under alternative regulation regimes. International Journal of Geographical Information Science, v. 14, n. 7, p. 625-648, 2000. 